\title{
RESISTANCE WELDING OF SHAPE-MEMORY COPPER-ALUMINIUM ALLOY
}

\author{
B.E. PATON ${ }^{1}$, D.M. KALEKO ${ }^{1}$, S.N. KEDROVSKY ${ }^{2}$, Yu.N. KOVAL ${ }^{2}$, \\ I.V. KRIVTSUN ${ }^{1}$ and V.N. SLEPCHENKO ${ }^{2}$ \\ ${ }^{1}$ E.O. Paton Electric Welding Institute, NASU \\ 11 Bozhenko Str., 03680, Kiev, Ukraine. E-mail: office@paton.kiev.ua \\ ${ }^{2}$ G.V. Kurdyumov Institute for Metal Physics, NASU \\ 36 Acad. Vernadsky Blvd., 03680, Kiev, Ukraine. E-mail: metall@imp.kiev.ua
}

\begin{abstract}
$\mathrm{Cu}-\mathrm{Al}$ based shape-memory alloys (SMA) are an attractive replacement for expensive SMA of $\mathrm{Ti}-\mathrm{Ni}$ system in fasteners, thermal automatic device activators, and superelastic elements of instrumentation. Therefore, the problem of joining the latter in different combinations with similar material and other structural metals has become urgent. The main requirement to such joints, in addition to strength, is preservation of functional characteristics, namely temperature range of shape restoration at thermoelastic martensite transformation. Weldability of $\mathrm{Cu}-\mathrm{Al}$ alloys in the form of $0.05 \mathrm{~mm}$ thick foil, $0.3 \mathrm{~mm}$ thick strip and $1 \mathrm{~mm}$ diameter wire by spot and butt capacitor-type welding was studied, and it was shown that at pulsed welding heating the functional characteristics in the welding area are preserved in joints with rupture strength, corresponding to the respective base metal strength. Metallographic examination showed recrystallization of the initial coarse-crystalline metal in welding heating zone with formation of fine-crystalline structure, both in the solid-state joints and around the cast nugget in spot welding of $0.3 \mathrm{~mm}$ strip. Sound butt joints of SMA and copper wire were produced. 5 Ref., 1 Table, 10 Figures.
\end{abstract}

$\boldsymbol{K} \boldsymbol{e} \boldsymbol{y} \boldsymbol{w} \boldsymbol{O} \boldsymbol{d} \boldsymbol{s}: \quad$ shape-memory alloys, copper-aluminium alloys, resistance spot welding, resistance butt welding, thermoelastic martensite transformation

Alloys characterized by thermoelasticity effect, so-called shape-memory alloys (SMA), are ever wider applied in medical engineering products (implants, prostheses, instruments), as part of thermal instrument activators and in mounting devices for tight mechanical joints, for instance, of pipelines.

The most widely accepted today are alloys based on NiTi intermetallic of almost equiatomic composition (nitinol) with alloying additives, enhancing their functional capabilities. The main advantage of nitinol is its bioinertness and atoxicity, that is critical in manufacture of medical engineering products. In other applications superplasticity inherent to nitinol is used, which is manifested at temperatures above the end of austenite transformation [1-3].

Nitinol is not the only known SMA. Thermoelasticity phenomenon is observed in a number of other alloys, of which $\mathrm{Cu}-\mathrm{Al}$ alloys are the best adaptable to manufacture. Compared to nitinol, these alloys have such advantages as lowering of initial material cost and simplicity of their melting technology that is important in connection with expansion of SMA application in engineering, as well as temperature range of martensite transformations higher than that of nitinol [3].

Nitinol weldability, both in the solid, and in the molten state, was studied by a number of researchers. Analysis of these works [4] showed that the most efficient are joining processes with pulsed heating, when reactions of the change of NiTi stoichiometric state do not have enough time to run in the welding zone, with precipitation of phases with another chemical formula $\left(\mathrm{Ti}_{2} \mathrm{Ni}\right.$ and $\mathrm{TiNi}_{3}$ ). Such processes include spot and percussion capacitor-type welding of flat and roundshaped parts with the characteristic size of up to $1 \mathrm{~mm}$.

Considering the good prospects for $\mathrm{Cu}-\mathrm{Al}$ alloy application in engineering, searching for respective welding processes for small cross-section parts from these alloys remains urgent.

Investigations were conducted with $\mathrm{Cu}-\mathrm{Al}$ alloy samples, having mechanical characteristics and temperature of plasticity loss higher than those of binary alloy [3].

Chemical composition of the studied alloy in the initial condition was as follows, wt.\%: $0.162 \mathrm{Ni} ; 0.85 \mathrm{Co} ; 0.22 \mathrm{Fe} ; 3.79 \mathrm{Mn} ; 11.1 \mathrm{Al}$; $83.9 \mathrm{Cu}$.

Resistance welding of $\mathrm{Cu}-\mathrm{Al}$ system alloy was studied on samples from $50 \mu \mathrm{m}$ thick foil, $300 \mu \mathrm{m}$ thick strip and $1 \mathrm{~mm}$ diameter wire. Joint quality 
Optimum modes of spot capacitor-type welding of foil and strip from $\mathrm{Cu}-\mathrm{Al}$ SMA (capacitor capacitance of $200 \mu \mathrm{F}$, number of choke turns of 140)

\begin{tabular}{||c|c|c|c|}
\hline $\begin{array}{c}\text { Sample } \\
\text { (thickness, mm) }\end{array}$ & $\begin{array}{c}\text { Capacitor } \\
\text { charging } \\
\text { voltage, V }\end{array}$ & $\begin{array}{c}\text { Transformation } \\
\text { ratio }\end{array}$ & $\begin{array}{c}\text { Compression } \\
\text { force, daN }\end{array}$ \\
\hline Foil (0.05) & 600 & 200 & 15 \\
\hline Strip (0.30) & 750 & 150 & 30 \\
\hline
\end{tabular}

was assessed by mechanical strength, as well as by comparison of phase transition temperatures of the initial metal and the welded joint.

Overlap joints of flat samples were welded in capacitor-type TKM-17 machine [5]. Considering the high heat and electric conductivity of the tested material, special attention was given to electrode material selection. Experiments showed that in spot welding of foil, the best result is obtained with electrodes with a molybdenum insert, limiting heat removal from the welded joint, whereas in strip welding standard [5] electrodes from known M3Ts alloy can be used.

Parts surface did not require any special preparation, if it did not have scale after rolling.

Optimum welding mode (the Table) was determined by the results of mechanical tensile testing of samples, made from foil, in tensile testing machine RMU-005-01, and testing strip samples in R-05 machine.

Samples of resistance butt welding of wire were produced in a laboratory machine, using discharge current of supercapacitors, ensuring constant electric characteristics during welding. As shown by oscillogram (Figure 1), welding current value practically does not change at discharge of supercapacitors of $50 \mathrm{~F}$ capacitance for $40 \mathrm{~ms}$. This makes the process of welding by supercapacitor discharge similar to direct current welding. Here there is no need to trace distortions of current associated with its rectification.

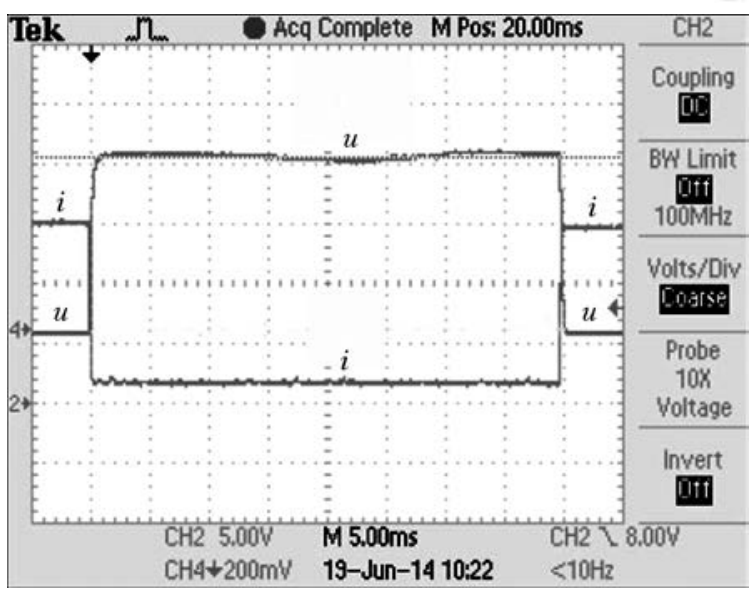

Figure 1. Oscillogram of supercapacitor discharge current and electric voltage on samples, joined in butt welding of $0.8 \mathrm{~mm}$ diameter copper and $1.0 \mathrm{~mm}$ diameter $\mathrm{Cu}-\mathrm{Al}$ based SMA

Capacitor charging voltage $(7-30 \mathrm{~V})$, discharge duration $(2-10 \mathrm{~ms})$, and compression forces $(30-50 \mathrm{~N})$ were the mode variables. Current and heating time values were monitored with TDS 2004 oscillograph. Joint quality was determined by welded sample bending (similar joints) and tension (including copper wire joints) in RMU-0.05-01 machine. Samples failing at not less that $2-3 \mathrm{~mm}$ from butt plane in bending were considered sound.

Welded joint microstructure was studied in AXIOVERT 40 MAT microscope.

Characteristic temperatures of martensite transformation of samples of $\mathrm{Cu}-\mathrm{Al}$ complex alloy were monitored by measurement of temperature dependence of electric resistance.

At tensile testing of samples from both foil and strip, joined by spot welding, the joint fails with material tearing out (Figure 2). Torn-out strip portion (Figure 3 ) has the shape of a regular circle, that would correspond to electrode contact surface, but it is elongated in the direction of load application, and the torn-put part of the joint is conical.
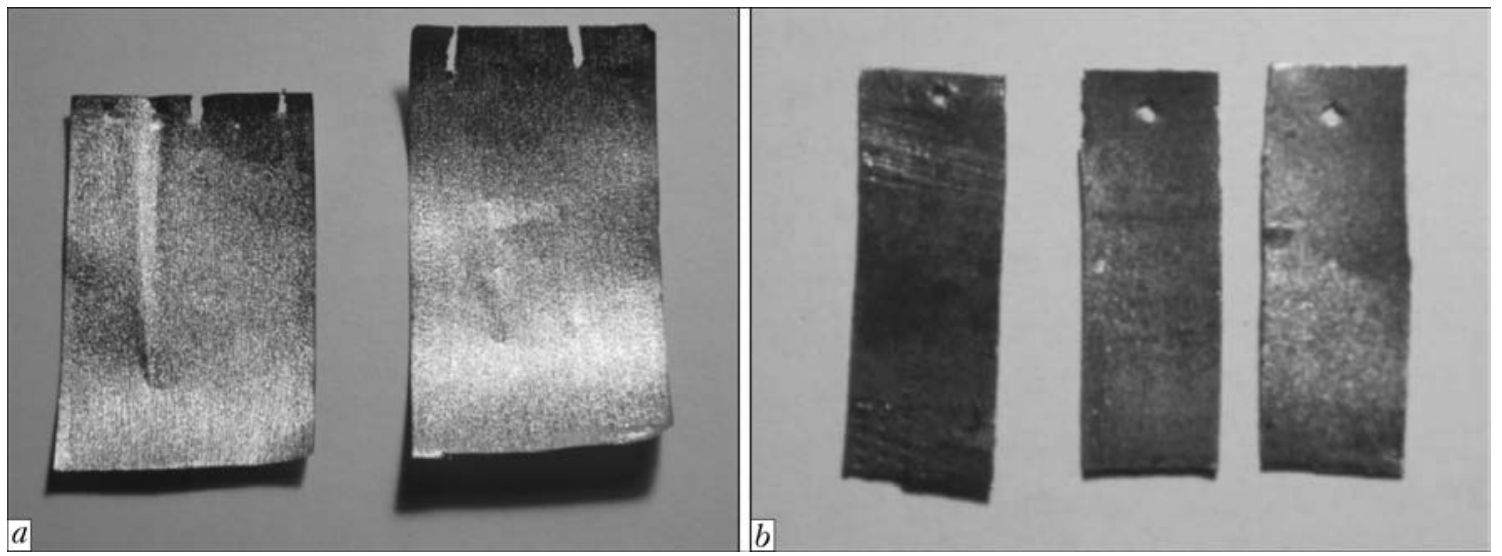

Figure 2. Samples made by spot capacitor-type welding after rupture testing: $a-$ foil $0.05 \mathrm{~mm}$ thick; $b-0.3 \mathrm{~mm}$ thick strip 
SCIENTIFIC AND TECHNICAL
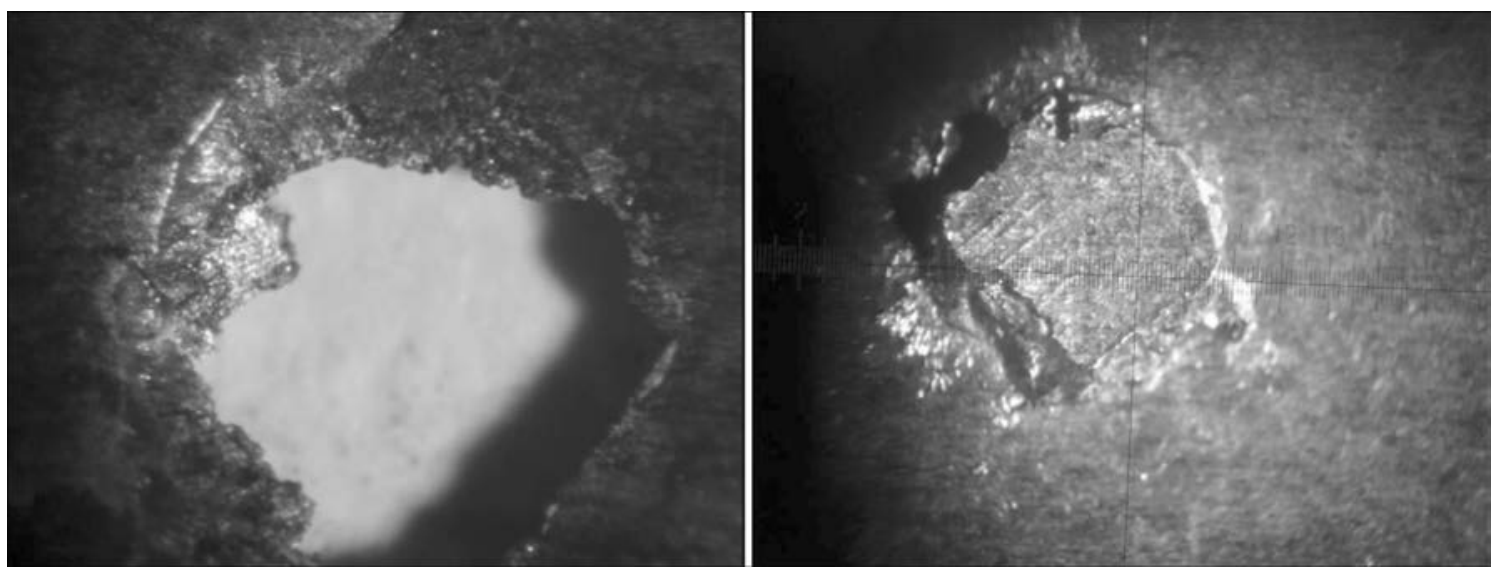

Figure 3. Shape of fracture of spot joint of $0.3 \mathrm{~mm}$ thick strip after tensile loading
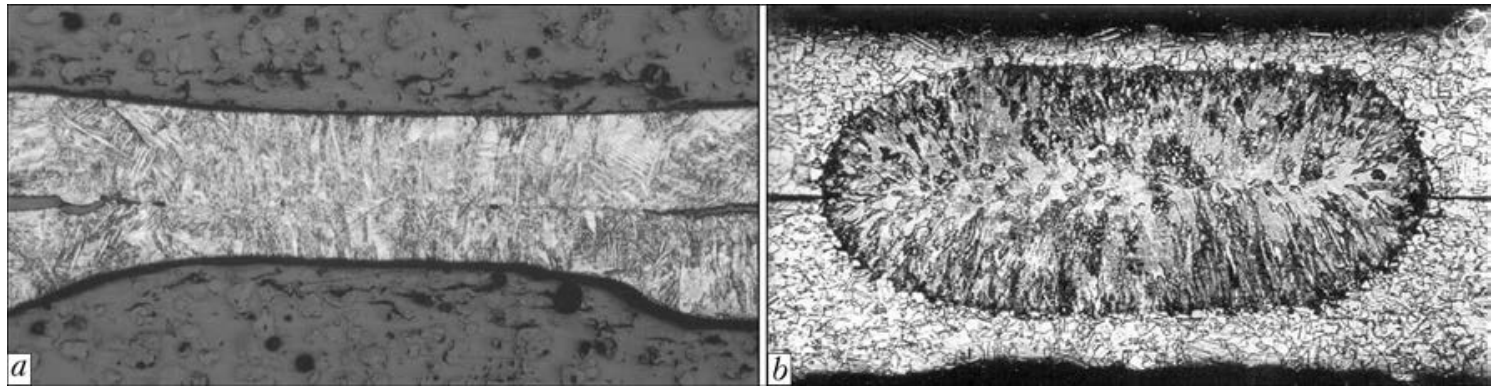

Figure 4. Microstructure of spot joint of $0.05 \mathrm{~mm}$ thick foil $(a-\times 300)$ and $0.3 \mathrm{~mm}$ thick strip $(b-\times 100)$

To improve measurement accuracy, experiments on foil $25 \mathrm{~mm}$ wide were conducted with different number of spots in the joint (from 2 up to 5 spots in a row). Average strength of one spot in such joints was equal to 0.46 daN. Breaking force of strip spot joint was equal to $80( \pm 5)$ daN.

Metallographic analysis of the structure of spot welded samples of material of different thickness $(50$ and $300 \mu \mathrm{m})$ showed a significant difference in the type of joint formation. While at foil spot welding, considering the high specific load in welding, the joint was produced in the solid state (Figure 4, $a$ ), a cast nugget formed in the strip joint (Figure 4, $b$ ).

Comparison of the structure of the joint central zone and its periphery showed (Figure 5) that the metal of foil, used in this study, has initial coarse-grained structure, which was formed as a result of annealing during drawing in fabrication. In solid-state spot welding, however, metal recrystallization in the heating zone and formation of columnar crystallites in the heat removal direction took place.

Owing to a pulsed heating mode in welding by a capacitor discharge, the joint zone is short, and structural changes, found during investigation, do not affect the functional properties of SMA.

In $0.05 \mathrm{~mm}$ samples, the most sensitive to heating, temperature dependence of electrical resistance in the state before and after welding was studied. It is found that no change of martensite transformation parameters is observed in the met-
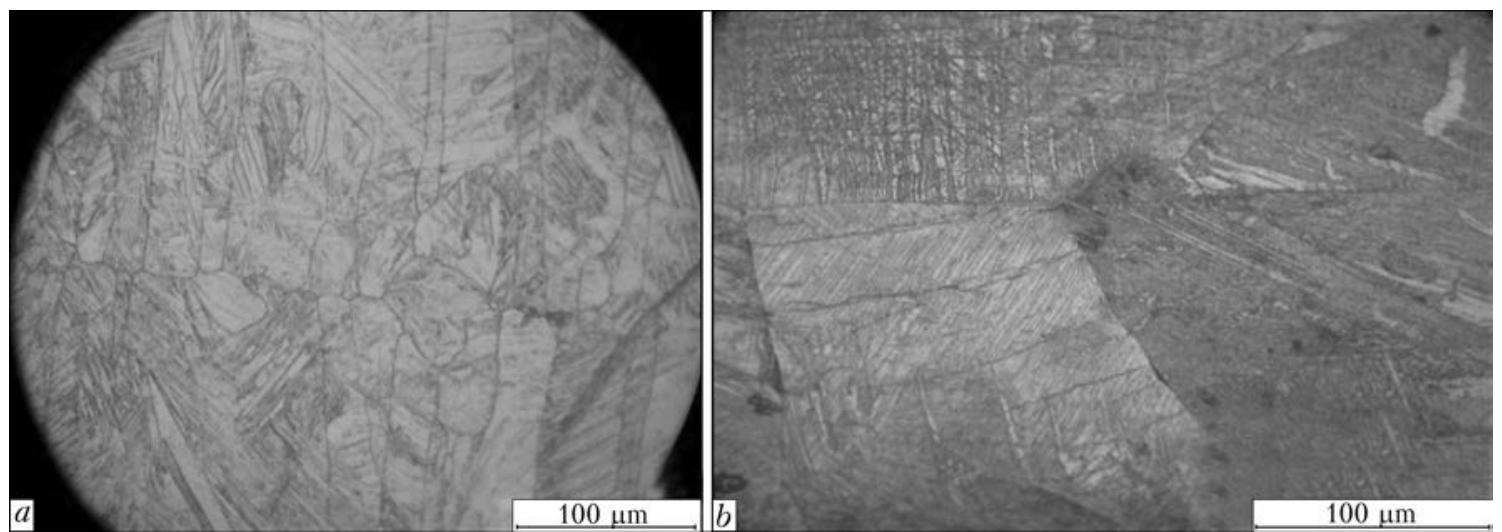

Figure 5. Microstructure of zone of foil spot welding: $a-$ central part; $b$ - base metal 

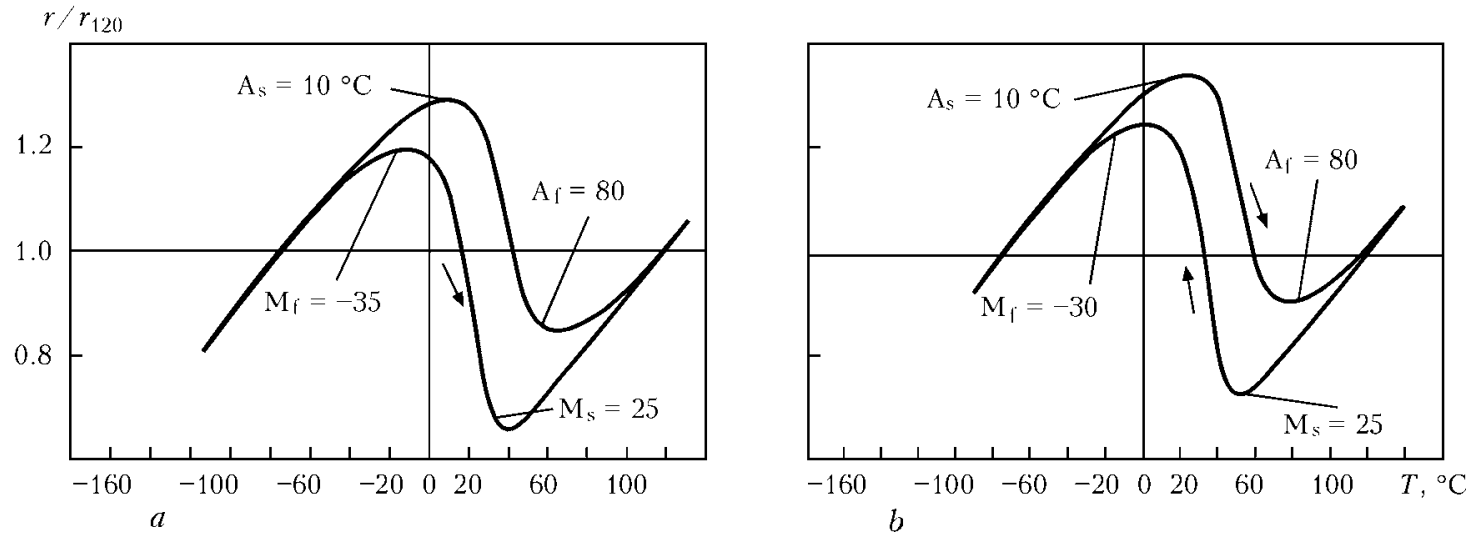

Figure 6. Temperature dependence of electrical resistance of samples outside $(a)$ and near $(b)$ the HAZ: $r_{120}-$ resistance at $120{ }^{\circ} \mathrm{C}$
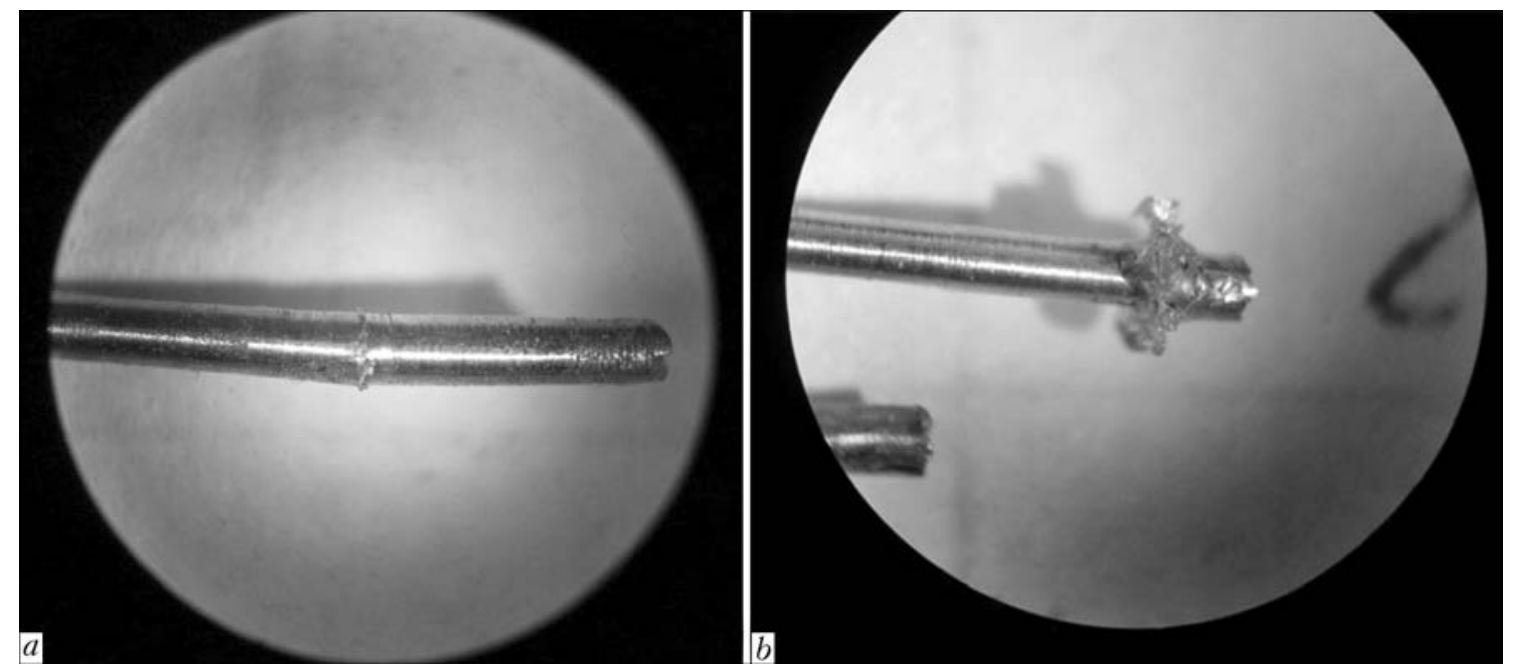

Figure 7. Appearance of butt joints of $1 \mathrm{~mm}$ diameter wire: $a$ - after welding (1250 A, $4.7 \mathrm{~ms}) ; b$ - after bend testing (610 A, $100 \mathrm{~ms})$

al not subjected to thermal impact (Figure 6, $a$ ). A certain increase of the temperature of the end of martensite transformation is observed near the HAZ (Figure $6, b$ ). It does not seem possible to study the weld zone for presence and parameters of martensite transformation, in view of its small dimensions.

Appearance of butt joints of $1 \mathrm{~mm}$ wire from $\mathrm{Cu}-\mathrm{Al}$ alloy, welded in different modes, is shown in Figure 7.

Metallographic examination showed (Figure 8) that in butt welding of the studied alloy, joining occurs in the solid state, with random formation of common grains. A characteristic feature of the microstructure near the interface is presence of scratches, which cannot be removed by polishing. Unlike spot welding (see Figure 5) in solid-state welding the metal initial structure does not change. Heat removal into the collet steel terminals in butt welding is much smaller than that into spot machine copper electrodes.

Note that metallographic investigations of butt joints were conducted on samples, which had withstood bending with fracture running beyond the butt joint.

Resistometry showed that, similar to investigation of samples of strip and foil spot joints, no change of martensite transformation temperature

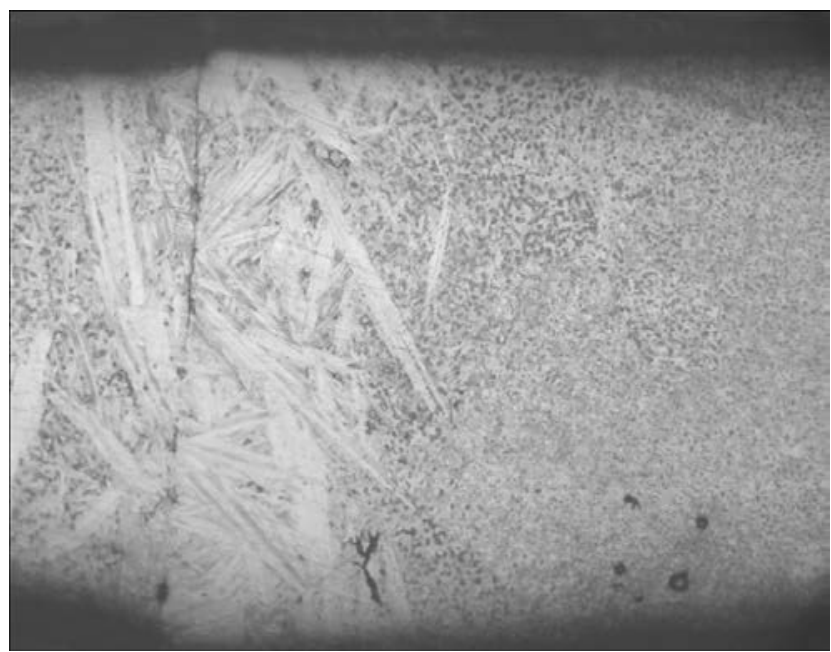

Figure 8. Microstructure $(\times 100)$ of joint of two $1 \mathrm{~mm}$ diameter wires from $\mathrm{Cu}-\mathrm{Al}$ alloy produced by butt capacitortype welding 

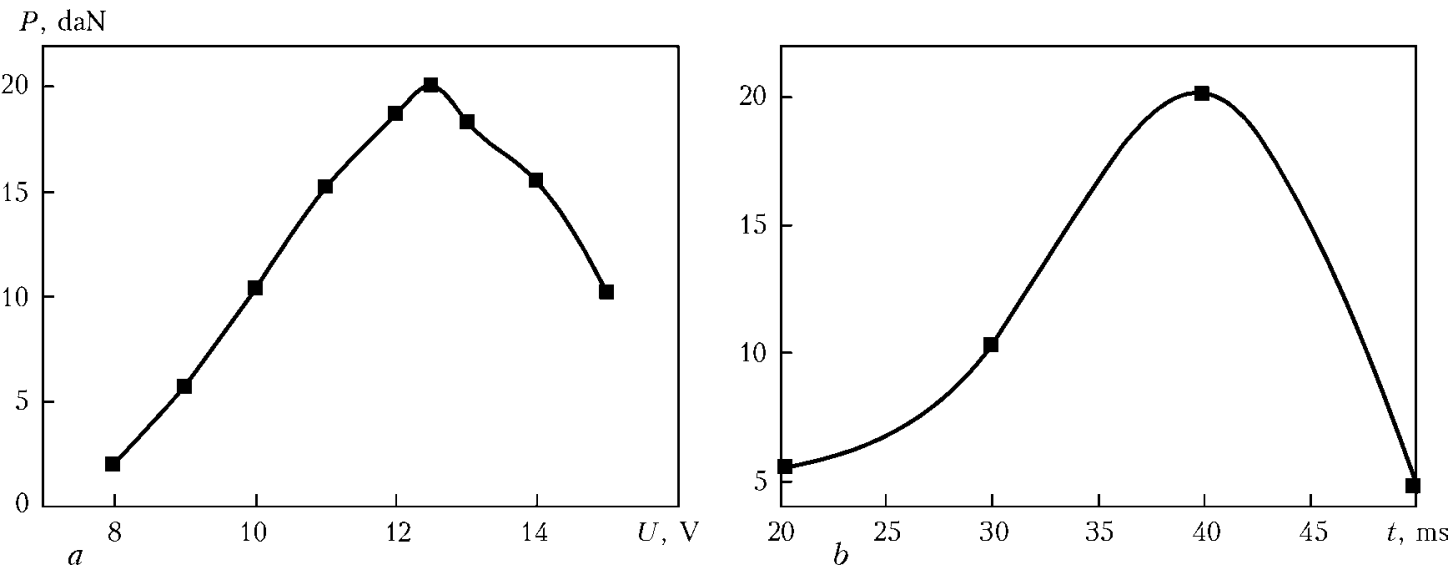

Figure 9. Dependence of strength of butt joints of copper wire with wire of $\mathrm{Cu}-\mathrm{Al}$ based complex alloy on supercapacitor charging voltage at $t=40 \mathrm{~ms}(a)$ and time of welding current running at $U=12.5 \mathrm{~V}(b)$

is observed in the peripheral zone of butt-welded joint.

Joints of functional material with structural metal, particularly with highly conductive copper and aluminium, are of practical importance.

Butt joints of $\mathrm{Cu}-\mathrm{Al}$ based complex alloy $(1.0 \mathrm{~mm}$ diameter wire) with copper wire $(0.8 \mathrm{~mm}$ diameter $)$ were studied. Maximum strength of the joint, determined by tensile testing, was obtained at supercapacitor charging voltage of $12.5 \mathrm{~V}$, welding current of $1152 \mathrm{~A}$ (see Figure 1), discharge duration of $40 \mathrm{~ms}$, length of copper wire free end of $2 \mathrm{~mm}$ and that of $\mathrm{Cu}-\mathrm{Al}$ SMA wire of $3 \mathrm{~mm}$, and upset force of $30 \mathrm{~N}$. Low longitudinal stability of copper was taken into account at selection of the sample free end length. It is also interesting to note lowering of voltage in the parts being welded in the oscillogram, associated, in our opinion, with increase of contact area. This proceeds for up to $25 \mathrm{~ms}$, which is followed by voltage increase, in keeping with increase of resistance of the parts being welded at heating.

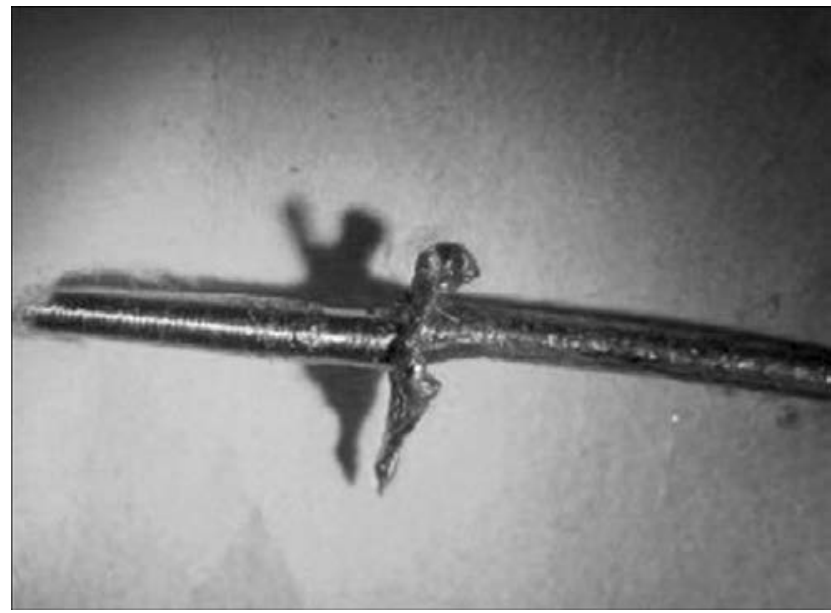

Figure 10. Sample of joint of $0.8 \mathrm{~mm}$ diameter copper wire (right) with $1.0 \mathrm{~mm}$ diameter $\mathrm{Cu}-\mathrm{Al}$ based alloy wire (left) produced by butt capacitor-type welding at $I=1152 \mathrm{~A}$ and $t=40 \mathrm{~ms}$
During investigations, welding time and capacitor charging voltage, which determines welding current value, were varied. Results of the dependence of joint strength on the mode variable parameters are given in Figure 9. As capacitor discharge voltage is measured much more accurately than the pulsed discharge current, the first was selected as the argument.

Dependencies of welded joint strength on charging voltage and welding current flowing time show the presence of mode parameter minimum. While strength improvement at increase of capacitor charging voltage (welding current value) and discharge time is readily explained by increase of joint area at increase of energy consumed in welding, strength lowering after passing the extremum point, as shown by studying the welded samples, is associated with melting out of a considerable amount of material ( $\mathrm{Fi}$ gure 10). As a result, at optimum value of the second parameter, the remaining solid metal in welding head clamps was insufficient for its reliable deformation at upsetting. Now, increase of wire extension from the collet clamp led to loss of longitudinal stability. At increase of mode parameters above those given in Figure 9, strength dropped to zero, as the wire was completely melted out right up to collet clamp contact.

A feature of dissimilar metal butt joints is more intensive heating of wire from $\mathrm{Cu}-\mathrm{Al}$ based complex alloy, compared to copper wire, having high electrical conductivity, despite its smaller diameter.

Thinning of wire from $\mathrm{Cu}-\mathrm{Al}$ based alloy, as a result of ductility increase at heating and ductile metal compression by the collet, is observed in welded samples (Figure 10), as well as noticeable upsetting of the copper wire. Owing to upsetting, as shown by metallographic examinations, the joint formed in the solid phase with a continuous boundary. This ensured equivalent 
strength of the joint on the level of that of the copper wire, i.e. at tensile testing the breaking force reached $200 \mathrm{~N}$, or about $400 \mathrm{MPa}$.

Attempts at butt welding of aluminium wire and wire from $\mathrm{Cu}-\mathrm{Al}$ based alloy failed. This is accounted for by a large difference in thermomechanical properties of the material, namely preservation of elasticity of $\mathrm{Cu}-\mathrm{Al}$ alloy at the temperature of the loss of elasticity by aluminium and the associated loss of the wire shape before sufficient heating of the functional alloy.

\section{Conclusions}

1. Owing to their low cost, shape-memory alloys of $\mathrm{Cu}-\mathrm{Al}$ system have good prospects for engineering application in automatics systems of thermal devices, structural element fasteners, undergoing considerable deformation without mechanical fracture. This accounts for the urgency of development of the technology of their joining in similar combination and in combinations with other structural metals.

2. Overlap and butt joints of complex SMA on $\mathrm{Cu}-\mathrm{Al}$ base, produced by the methods of pulsed capacitor-discharge resistance welding, are not only equivalent to base metal, but also demonstrate practically constant functional characteristics.

3. Depending on deformational characteristics of the part, spot-welded joints of the studied alloy can be produced both with a cast nugget, as by solid-state adhesion. Here the surface films (except for scale) have no adverse impact on welded joints.

4. Butt joints of wire from $\mathrm{Cu}-\mathrm{Al}$ SMA with copper wire can be produced, that allows designing items with shape restoration at heating by passing electric current.

5. Application of new type of welding system with transformerless discharge of supercapacitors for butt welding of wires showed the possibility of accurate control of heat input by variation of the time of discharge current switching on at its practically constant value, assigned by capacitor discharge voltage. Oscillographing the successive discharges at constant setting of mode parameters allows assessment of deviation from the nominal energy value of not more than $0.5 \mathrm{~J}$.

1. Koval, Yu.N., Lobodyuk, V.A. (2010) Deformation and relaxation phenomena at transformation of martensite type. Kiev: Naukova Dumka.

2. Gunter, V.E., Khodorenko, V.N., Yasenchuk, Yu.F. et al. (2006) Titanium nickelide. Medical material of new generation. Tomsk: MITs.

3. Otsuka, K., Shimizu, K. (1979) Shape memory effects in alloys. Moscow: Nauka.

4. Paton, B.E., Kaleko, D.M., Shevchenko, V.P. et al. (2006) Weldability of shape-memory alloys of $\mathrm{Ni}-\mathrm{Ti}$ system. The Paton Welding J., 5, 2-7.

5. Moravsky, V.E., Vorona, D.S. (1985) Technology and equipment for spot and capacitor-discharge projection welding. Kiev: Naukova Dumka.

Received 01.09.2015 